\title{
Comparative genomic hybridization detects many recurrent imbalances in central nervous system primitive neuroectodermal tumours in children
}

\author{
H Avet-Loiseau ${ }^{1}$, A-M Vénuat ${ }^{2}$, M-J Terrier-Lacombe ${ }^{3}$, A Lellouch-Tubiana $^{5}$, M Zerah $^{6}$ and G Vassal ${ }^{4}$ \\ ${ }^{1}$ Laboratory of Hematology, Institut de Biologie, 9 quai Moncousu, 44093 Nantes Cédex 1, France; 'Laboratory of Genetics and Cytogenetics, ${ }^{3}$ Department of \\ Pathology, ${ }^{4}$ Department of Pediatric Oncology and CNRS URA 147, Institut Gustave Roussy, 39 rue Camille Desmoulins, 94805 Villejuif Cédex, France; \\ ${ }^{5}$ Department of Pathology, ${ }^{6}$ Department of Pediatric Neurosurgery, Hopital Necker-Enfants Malades, 149 rue de Sevres, 75743 Paris Cedex 15 , France
}

\begin{abstract}
Summary A series of 23 children with primitive neuroectodermal tumours (PNET) were analysed with comparative genomic hybridization (CGH). Multiple chromosomal imbalances have been detected in 20 patients. The most frequently involved chromosome was chromosome 17 , with a gain of $17 q$ (11 cases) and loss of $17 p$ (eight cases). Further recurrent copy number changes were detected. Extra copies of chromosome 7 were present in nine patients and gains of $1 q$ were detected in six patients. A moderate genomic amplification was detected in one patient, involving two sites on $3 p$ and the whole 12p. Losses were more frequent, and especially involved the chromosomes 11 (nine cases), 10q (eight cases), 8 (six cases), X (six patients) and 3 (five cases), and part of chromosome 9 (five cases). These recurrent chromosomal changes may highlight locations of novel genes with an important role in the development and/or progression of PNET.
\end{abstract}

Keywords: CGH; PNET; medulloblastoma; FISH; cytogenetics

Primitive neuroectodermal tumours (PNET) are the most frequent primary malignant childhood brain tumours (Farwell et al, 1977; Bigner et al, 1988). Medulloblastomas represent the majority of cerebral PNET and are located in the cerebellum. Because of difficulties in generating adequate metaphases, cytogenetic data in these tumour types are still limited. The most frequent abnormality is isochromosome $\mathrm{i}(17 \mathrm{q})$, found in approximately $30 \%$ of cases analysed with conventional cytogenetics (Bigner et al, 1988; Griffin et al, 1988; Biegel et al, 1989; Karnes et al, 1992; VagnerCapodano et al, 1992; Neumann et al, 1993; Fujii et al, 1994). This high incidence of $\mathrm{i}(17 \mathrm{q})$ was confirmed in a molecular cytogenetic study, which also showed deletions of $17 \mathrm{p}$ in $44 \%$ of patients (Biegel et al, 1995). Other studies using molecular approaches confirmed this frequent loss of $17 \mathrm{p}$, and localized a hot-spot of loss of heterozygosity at $17 \mathrm{p} 13.3$, a locus telomeric to the p53 gene (Biegel et al, 1992; Cogen et al, 1992; McDonald et al, 1994; Batra et al, 1995). A very recent deletion mapping study localized a common chromosomal disruption within a more centromeric region, at 17p11.2 (Scheurlen et al, 1997). Other recurrent abnormalities have been described, including structural aberrations of chromosomes 1, 3, 6, 11, 16 and X, loss of chromosome 22 and gains of chromosomes 6 and 8 (Farwell et al, 1977; Bigner et al, 1988, 1990; Griffin et al, 1988; Callen et al, 1989; Karnes et al, 1992; Neumann et al, 1993; Fujii et al, 1994). Few gene amplifications have been reported, involving $M Y C, M Y C N$ or EGFR (Rouah

Received 19 May 1998

Revised 25 August 1998

Accepted 18 September 1998

Correspondence to: $\mathrm{H}$ Avet-Loiseau, Laboratory of Hematology, Biology Institute, 9 quai Moncousu, 44093 Nantes Cedex, France et al, 1989; Wasson et al, 1990; Fuller and Bigner, 1992; Badiali et al, 1995), and more recently the 5p15 and 11q22 chromosomal regions (Reardon et al, 1997).

The recently developed technique of comparative genomic hybridization (CGH) allows a genome-wide screening for unbalanced abnormalities, without the requirement for tumour metaphases (reviewed in Kallioniemi et al, 1994). Only two studies using this approach in PNET have previously been reported (Schutz et al, 1996; Reardon et al, 1997). In order to extend our knowledge on recurrent imbalances in this disease, we analysed frozen tumour samples obtained from 23 children with either medulloblastoma (21 patients) or supratentorial PNET (two patients). We found many recurrent abnormalities, especially gains of $17 \mathrm{q}, 1 \mathrm{q}$ and 7 , and losses of chromosomes 3, 8, 10q, 11, 21 and $\mathrm{X}$.

\section{MATERIALS AND METHODS}

\section{Patients}

Primary brain tumour tissue samples were obtained from 23 patients with a PNET. Samples were obtained at diagnosis in 22 patients and at time of relapse in 1 patient, a 13-year-old boy with a non-metastatic medulloblastoma (patient 221) (Table 1). There were 11 girls and 12 boys with a median age of 7.5 years (range 9 months-13 years). Twenty-one patients had a cerebellar tumour, i.e. medulloblastoma, and two a supratentorial PNET. The disease was metastatic at diagnosis in nine patients with newly diagnosed medulloblastoma, as assessed by magnetic resurance imaging (MRI) and cerebrospinal fluid (CSF) analysis. Tissue samples were immediately frozen in liquid nitrogen upon tumour removal and stored at $-80^{\circ} \mathrm{C}$ until analysis. For histological analysis, tissue 
Table 1 Main clinical characteristics and CGH results of the 23 patients

\begin{tabular}{|c|c|c|c|c|c|c|c|}
\hline \multirow{2}{*}{$\begin{array}{l}\text { Patient } \\
\text { no. }\end{array}$} & \multirow{2}{*}{ Sex } & \multirow{2}{*}{$\begin{array}{c}\text { Age } \\
\text { (years) }\end{array}$} & \multirow{2}{*}{ Histology } & \multirow{2}{*}{ Tumour location } & \multirow[t]{2}{*}{ Metastasis } & \multicolumn{2}{|c|}{ CGH results } \\
\hline & & & & & & Gains & Losses \\
\hline 89 & $\mathrm{~F}$ & 3 & Medulloblastoma & Posterior fossa & No & $6,8,13,17 q$ & $4 q, 10,11,21, x$ \\
\hline 99 & $\mathrm{~F}$ & 4 & $\begin{array}{l}\text { PNET with glial } \\
\text { component }\end{array}$ & Supratentorial & No & $1 q, 2,17$ & \\
\hline 107 & M & 9 & Medulloblastoma & Posterior fossa & No & $7,17 q$ & $2 q 14 q 33,3,11,17 p$ \\
\hline 127 & M & 9.7 & Medulloblastoma & Posterior fossa & No & 1q, 2, 12q22qter, 17q & $3,8,10,11,17 p$ \\
\hline 161 & M & 4.1 & Medulloblastoma & Posterior fossa & No & $5,7,17 q$ & $3,8,11,15,17 p, 20$ \\
\hline 202 & M & 12.2 & Medulloblastoma & Posterior fossa & No & 7 & $2,3,8$, 9pterq22, 13, 15, 20 \\
\hline 208 & M & 4.2 & $\begin{array}{l}\text { PNET with glial } \\
\text { component }\end{array}$ & Supratentorial & No & & 9pterq22, 11q23qter \\
\hline 221 & M & 13 & Medulloblastoma & Posterior fossa & * & $7, x$ & $8 p, 10 q, 11,13$ \\
\hline 222 & M & 6.4 & Medulloblastoma & Posterior fossa & No & 3pterp24, 3p23p21, 12p & $17 p$ \\
\hline 223 & $\mathrm{~F}$ & 12.7 & Medulloblastoma & Posterior fossa & No & & 6 \\
\hline 228 & M & 8.9 & Medulloblastoma & Posterior fossa & No & $1 q, 7,17 q$ & $9 p 21 q 21$ \\
\hline 234 & M & 12 & Medulloblastoma & Posterior fossa & No & 1p31qter, $4,5,7,18$ & $8,9,10,11,12 \mathrm{p} 12 \mathrm{q} 14,16,21$ \\
\hline 245 & $\mathrm{~F}$ & 7.5 & Medulloblastoma & Posterior fossa & No & 1q31qter, 3q, 13, Xq & $3 p, 10 q, 14 q 21 q t e r$ \\
\hline 249 & $\mathrm{~F}$ & 7.7 & Medulloblastoma & Posterior fossa & No & $4,7,17$ & $8,10,11,15 q 11 q 15, X$ \\
\hline 77 & $\mathrm{~F}$ & 6.6 & Medulloblastoma & Posterior fossa & Yes & 7,12 pterq12, 15q25qter, $17 q$ & $3,13,17 p, X$ \\
\hline 81 & $\mathrm{~F}$ & 6.9 & Medulloblastoma & Posterior fossa & Yes & $1 q, 5,6,8 q$ & $7 p, 21, x$ \\
\hline 84 & $\mathrm{~F}$ & 2.2 & Medulloblastoma & Posterior fossa & Yes & $7,10 p, 13,14,17$ & $4,8,10 q, 11,15,21, X$ \\
\hline 113 & M & 1.4 & Medulloblastoma & Posterior fossa & Yes & $2,6 q 10 q 24$ & 16p, 17pterq23 \\
\hline 164 & $\mathrm{~F}$ & 11 & Medulloblastoma & Posterior fossa & Yes & & Normal \\
\hline 207 & $\mathrm{~F}$ & 1.2 & Medulloblastoma & Posterior fossa & Yes & & Normal \\
\hline 212 & $\mathrm{~F}$ & 3.9 & Medulloblastoma & Posterior fossa & Yes & 1031qter, 7q, 13q31qter, 17q & $10 q, 17 p, x$ \\
\hline 214 & M & 0.7 & Medulloblastoma & Posterior fossa & Yes & & Normal \\
\hline 227 & M & 9.5 & Medulloblastoma & Posterior fossa & Yes & 4q22qter, 17q & $9 p 13 q 21,17 p, 20$ \\
\hline
\end{tabular}

aTumour sample was obtained at time of relapse. M, male; F, female.

specimens were fixed in acetic acid-formalin-ethanol (AFA; Carlo-Erba, Milan, Italy) and embedded in paraffin. Paraffinembedded sections were then routinely stained with haematoxylin-eosin-saphranin (HES). Appropriate immunohistochemical analysis was performed when needed to rule out a differential diagnosis, especially for supratentorial tumours.

\section{Comparative genomic hybridization}

CGH was performed as previously described (Paszek-Vigier et al, 1997). Briefly, tumour DNA was extracted using phenol-chloroform technique. Tumour DNA was labelled by nick translation with Texas red (TR)-dUTP (Dupont-NEN), whereas normal DNA from heathy male and female donors was labelled with fluorescein isothiocyanate (FITC)-dUTP (Dupont-NEN). A total of $150 \mathrm{ng}$ of each donor's DNA and $20 \mu \mathrm{g}$ of unlabelled Cot-1 DNA (Gibco, BRL) were ethanol precipitated, resuspended in Hybrisol VII (Oncor, Gaithersburg, MD, USA) and denatured for $10 \mathrm{~min}$. After a 48 -hour hybridization at $37^{\circ} \mathrm{C}$, slides were washed for $5 \mathrm{~min}$ in
$2 \times$ saline-sodium citrate $(\mathrm{SSC})$ at $73^{\circ} \mathrm{C}$ and examined using an epifluorescence microscope (DMRB, Leica). CGH analysis was performed using Powergene software (PSI, Houston, TX, USA). The over- and under-represented DNA segments were determined by calculating TR:FITC average ratio profiles. Average ratio images were calculated from at least six metaphases and had fixed thresholds. Chromosomal gains were considered when fluorescence ratios exceeded 1.15 and losses were considered for ratios lower than 0.85 . Telomeric and heterochromatic regions were excluded from analysis, according to Kallioniemi et al (1994), as well as chromosomes 1p, 16q, 19, 22 and Y. Genomic amplification was defined by a red/green ratio $>1.5$.

\section{RESULTS}

CGH analysis was successfully performed for the 23 tested patients. Figure 1 summarizes the copy number changes detected in the 23 patients. Twenty contained aberrations in at least one 


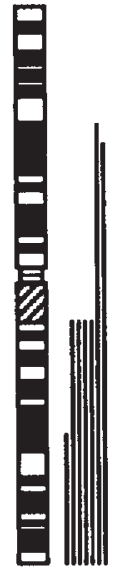

1
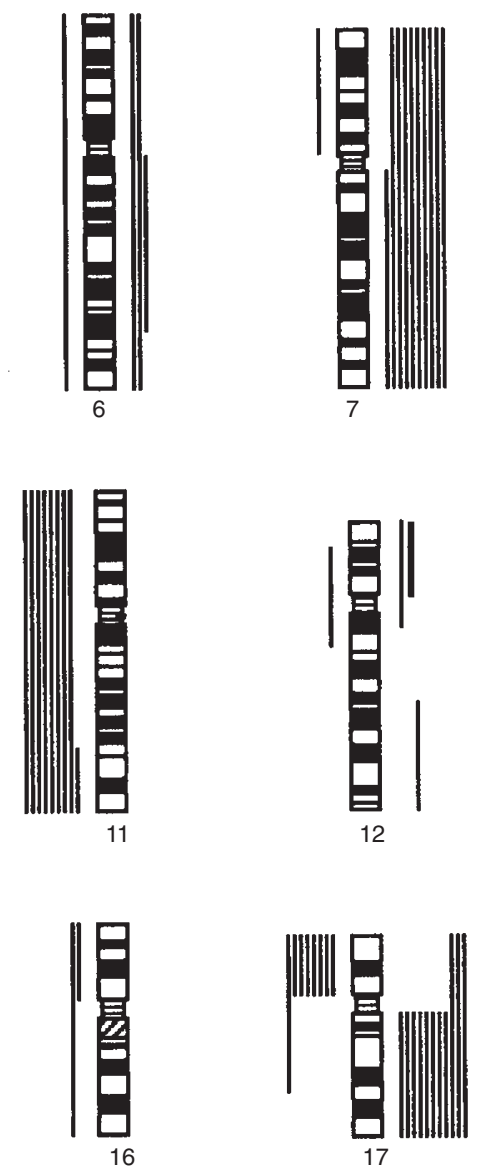

曷
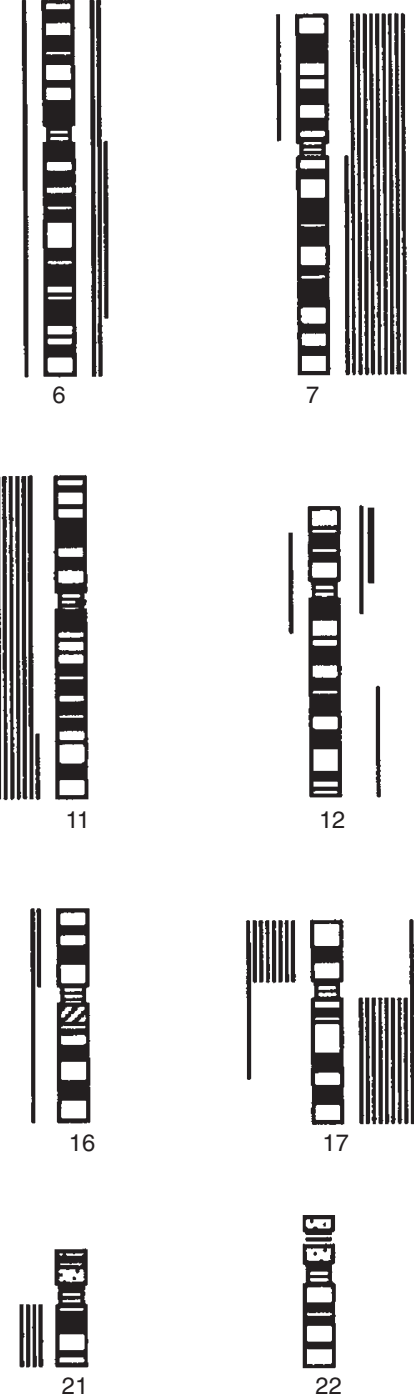
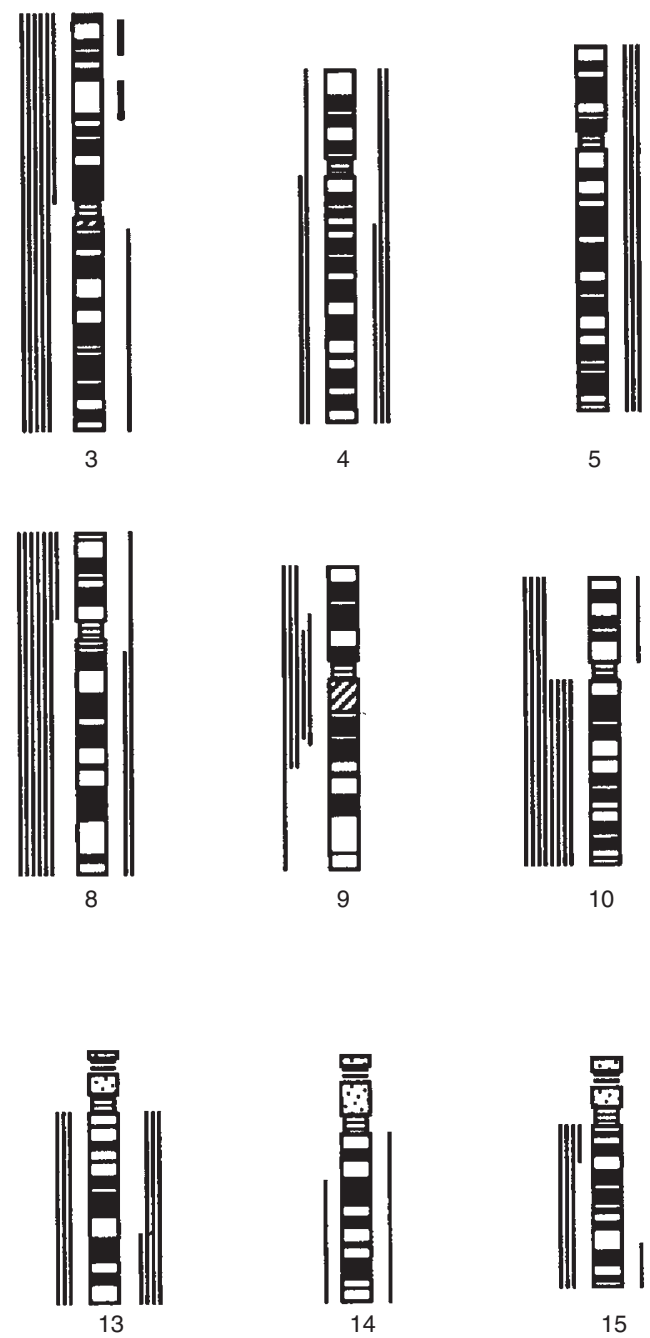
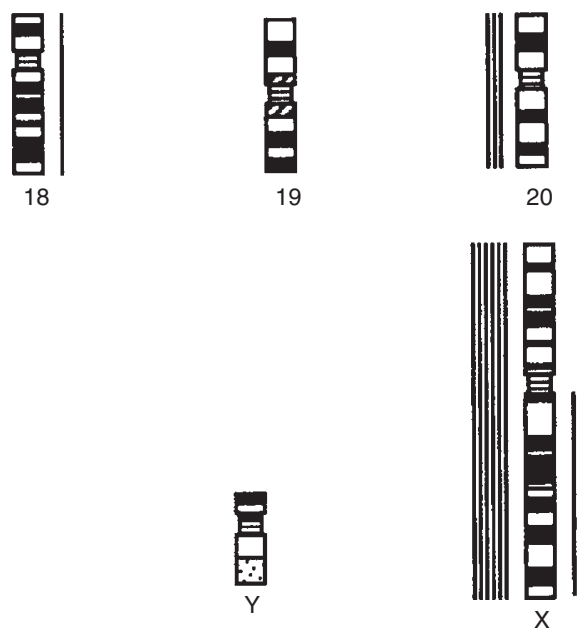

Figure 1 Summary of the chromosomal gains and losses found in this series. Vertical lines on the right side of a chromosome represent a gain of genetic material and a vertical line on the left side a loss of material. Thick lines show genomic amplifications 
3

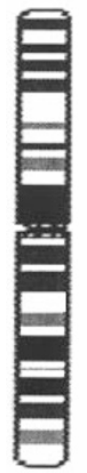

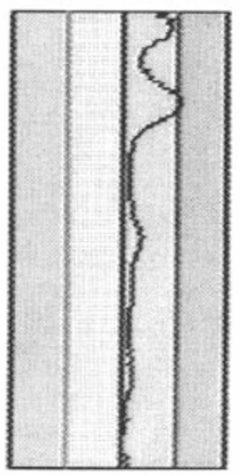

$n=8$

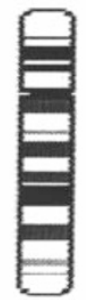

12

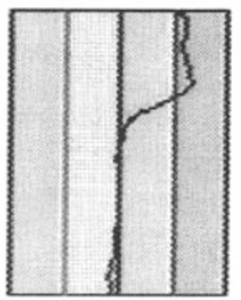

$n=10$
Figure 2 A partial CGH 'karyotype' showing low-level amplifications on chromosomes 3 (averaged profile from eight copies of chromosome 3 ) and 12 (averaged profile from ten copies of chromosome 12) (patient 222). The median thick line represents the ratio 1 , the left line the ratio 0.5 and the right line the ratio 1.5. This patient displays two different amplified regions on the short arm of chromosome 3 and multiple copy numbers of the short arm of chromosome 12

chromosomal region. The number of imbalances ranged from 0 to 13 (median $=6)$. The most frequent abnormality was a gain of $17 \mathrm{q}$ in 11 cases. Other recurrent abnormalities were a gain of chromosome 7 (nine patients), loss of 11 (eight patients), loss of $17 \mathrm{p}$ (eight patients), loss of 10q (eight patients), loss of chromosome $\mathrm{X}$ (six patients), loss of 8 (six patients), gain of 1q (six patients) and loss of chromosomes 3 and 9p (five patients each). The coexistence of gain of $17 q$ and loss of $17 p$ in six patients was suggestive of an isochromosome i(17q). Multiple copy numbers involving $3 p$ and $12 p$ were found in one patient (Figure 2). No amplification was found at other classical amplified loci $(M Y C, M Y C N$ or $E G F R$ ). In the analyses, we also separated metastatic patients from children with localized disease. Among recurrent abnormalities described above, loss of chromosome 11 appeared to be less frequent in children with metastatic PNET.

\section{DISCUSSION}

CGH has been used for the identification of chromosomal imbalances in a wide variety of solid tumours and haematologic malignancies. This technique circumvents many limitations associated with conventional cytogenetics, such as the difficulty to obtain metaphases in tumour cells or the often poor quality of chromosome spreads associated with the frequent high-complexity of chromosomal changes. Moreover, CGH does not require fresh tumour material, and even small pieces of tumour can be analysed. For all these reasons, $\mathrm{CGH}$ is a very powerful technique for the analysis of chromosomal changes in solid tumours. However, some limitations exist. Balanced chromosomal rearrangements are not detected and some regions, including 1p, 16q, 19, 22 and Y, are difficult to analyse. In this study, we detected chromosomal imbalances in 20 out of 23 tumours analysed. No abnormality was detected in three patients with metastatic disease, corresponding either to patients with a normal karyotype or only balanced structural abnormalities, or to patients with an important contamination with normal cells. Losses were slightly more frequent than gains (75 versus 60), and many recurrent chromosomal changes were found.
In agreement with published cytogenetic data, chromosome 17 was the most frequently involved. Gain of $17 \mathrm{q}$ was found in 11 patients (half of the abnormal patients) and loss of $17 \mathrm{p}$ was found in eight patients. In six cases, both abnormalities were present simultaneously, indicating the probable presence of an $\mathrm{i}(17 \mathrm{q})$. Nevertheless, some patients have only gain of $17 q$ and others have only loss of $17 \mathrm{p}$, suggesting that these two abnormalities may involve different tumorigenic pathways. Recent data showed that different regions may be lost in $17 \mathrm{p}$ deletions, leading to the loss of different putative tumour suppressor genes (Biegel et al, 1992; Cogen et al, 1992; McDonald et al, 1994; Batra et al, 1995; Scheurlen et al, 1997). On the other hand, gain of chromosome $17 \mathrm{q}$ (through the formation of an isochromosome or an isolated gain of 17q) is probably an important second event, by modifying some gene dosage. This phenomenon has to be related to abnormalities described in another neuroectodermal tumour, i.e. neuroblastoma. Recently, it has been shown that gains of 17qter material were present in about $90 \%$ of high-grade neuroblastomas (Meddeb et al, 1996). Because neuroblastomas and medulloblastomas are both neuroectodermal tumours, a common tumorigenic event may be proposed, even if no candidate gene has so far been found.

We also found many other abnormalities, especially extra copies of chromosome 7 and losses of chromosomes 11 and 10q. Most of them are in agreement with data reported by Reardon et al (1997), but strongly differ from Schutz et al's data (1996). Both trisomy 7 and loss of chromosome 10 are the hallmark of another type of brain tumour, glioblastoma multiforme (Bigner et al, 1990). This tumour is especially frequent in adults, but rather rare in childhood. Moreover, embryologic origins of glioblastomas and medulloblastomas are totally different. The former is a glial tumour, whereas medulloblastoma is a neuroectodermal tumour. Are there common genetic abnormalities in childhood brain malignancies? This question has to be raised, but larger series will be needed to address this question.

Loss of 11q has already been reported in medulloblastomas (Callen et al, 1989; Vagner-Capodano et al, 1992; Reardon et al, 1997). Vagner-Capodano et al (1992) suggested that tumours with $11 \mathrm{q}$ abnormalities might constitute a subgroup of medulloblastoma different from tumours with an $\mathrm{i}(17 \mathrm{q})$. Our results do not support this hypothesis. In our series, six patients had abnormalities of both chromosome 11 and 17; three with monosomy 11 and an $i(17 q)$ and three with monosomy 11 and gain of chromosome 17 or $17 \mathrm{q}$. The loss of chromosome 11 was found to be more frequent in patients with localized disease (8/14 versus 1/9). Even if these respective frequencies are statistically different, a larger series would be necessary to conclude.

Other recurrent abnormalities were loss of chromosome $\mathrm{X}, 3,8$ and $9 \mathrm{p}-9 \mathrm{q} 21-22$, and gain of chromosome 1q. This latter abnormality is not a medulloblastoma-specific change since it has been described in a large variety of tumour types. Loss of chromosome $9 p$ has been reported in adult gliomas, but not in childhood medulloblastoma. In adults, it seems to lead to p15/p16 deletions (Jen et al, 1994; Barker et al, 1997). Interestingly, the five patients with a chromosome 9 deletion share a loss of the q21-22 region. Recently, mutations of the PTCH gene, which maps at 9q22, have been reported in medulloblastoma (Pietsch et al, 1997; Wolter et al, 1997). We can speculate that these deletions in our patients include this gene. Losses in chromosome 3 have not been reported as non-random changes in medulloblastomas. We found loss of chromosome 3 in five patients, plus one patient with loss of $3 p$ and 
gain of $3 q$ (suggesting the presence of an isochromosome $3 q$ ). The entire chromosome 8 was lost in six patients and another patient exhibited loss of chromosome $8 \mathrm{p}$. These losses of chromosome 8 material are in agreement with Reardon et al's data (1997), which found a recurrent loss of the short arm of chromosome 8. Many genes localized on $3 p$ or $8 p$ could potentially be the main target of these deletions, and more patients will be necessary to try to define the critical minimal deleted region.

No high-level amplification has been found in this study. Only one patient displayed multiple copy number changes: two gains on $3 p(3 p 21$ and 3 p25) and one gain of the entire chromosome 12 short arm. In these three cases, deviations from the baseline are compatible with multiple copy numbers. These regions have not been previously reported. Amplifications have rarely been reported in medulloblastomas, usually as double minutes. When analysed, the target genes of these amplifications were either MYC, MYCN or EGFR (Rouah et al, 1989; Wasson et al, 1990; Fuller and Bigner, 1992), and more recently the 5p15 and 11q22 regions (Reardon et al, 1997). None of these regions was amplified in our series.

In conclusion, this CGH study identified many non-random copy number changes, confirming data from the Reardon group (1997). Larger series of consecutive patients would define the exact frequency and significance of these individual chromosomal abnormalities. This analysis prompts the elaboration of large prospective studies in order to determine the potential prognostic significance of these copy number changes.

\section{ACKNOWLEDGEMENTS}

We thank Professor Alain Pierre-Kahn, Professor Christian SainteRose and all the staff of the Department of Pediatric Neurosurgery operating theater (Hopital Necker) for their help in providing us with brain tumour tissue samples. This study was supported by the Comite de Loire-Atlantique de la Ligue contre le Cancer.

\section{REFERENCES}

Badiali M, Pession A, Basso G, Andreini L, Rigobello L, Galassi E and Giangaspero $\mathrm{F}$ (1995) N-myc and c-myc oncogenes amplification in medulloblastoma: evidence of particularly aggressive behaviour of a tumor with c-myc amplification. Tumori 77: 118-121

Barker FG, Chen P, Furman F, Aldape KD, Edwards MS and Israel MA (1997) P16 deletion and mutation analysis in human brain tumors. J Neurdoncol 31: 17-23

Batra S, McLendon R, Koo JS, Castelino-Prabhu S, Fuchs H, Krischer J, Friedman H, Bigner D and Bigner H (1995) Prognostic implications of chromosome 17p deletions in human medulloblastomas. J Neurooncol 24: 39-45

Biegel JA, Rorke LB, Packer RJ, Sutton LN, Schut L, Bonner K and Emanuel BS (1989) Isochromosome 17q in primitive neuroectodermal tumors of the central nervous system. Genes Chromosomes Cancer 1: 139-147

Biegel JA, Burk CD, Barr FG and Emanuel BS (1992) Evidence for a 17p tumorrelated locus distinct from $\mathrm{p} 53$ in pediatric primitive neuroectodermal tumors. Cancer Res 52: 2347-2350

Biegel JA, Rorke LB, Janss AJ, Sutton LN and Parmiter AH (1995) Isochromosome $17 \mathrm{q}$ demonstrated by interphase fluorescence in situ hybridization in primitive neuroectodermal tumors of the central nervous system. Genes Chromosomes Cancer 14: 85-96

Bigner SH, Mark J, Friedman HS, Biegel JA and Bigner DD (1988) Structural chromosomal abnormalities in human medulloblastoma. Cancer Genet Cytogenet 30: 91-101

Bigner SH, Mark J and Bigner DD (1990) Cytogenetics of human brain tumors. Cancer Genet Cytogenet 47: 141-154
Callen DF, Cirocco L and Moore L (1989) A der(11)t(8;11) in two medulloblastomas: a possible non-random cytogenetic abnormality. Cancer Genet Cytogenet 38: 255-260

Cogen PH, Daneshvar L, Metzger AK, Duyk G, Edwards MS and Sheffield VC (1992) Involvement of multiple 17p loci in medulloblastoma tumorigenesis. Am J Hum Genet 50: 584-589

Farwell JR, Dohrmann GJ and Flanner JT (1977) Central nervous system tumors in children. Cancer 40: 3123-3132

Fujii Y, Hongo T and Hayashi Y (1994) Chromosome analysis of brain tumors in childhood. Genes Chromosomes Cancer 11: 205-215

Fuller GN and Bigner SH (1992) Amplified cellular oncogenes in neoplasms of the human nervous system. Mutat Res 276: 299-306

Griffin CA, Hawkins AL, Packer FJ, Rorke LB and Emanuel BS (1988) Chromosome abnormalities in pediatric brain tumors. Cancer Res 48: 175-180

Jen J, Harper JW, Bigner SH, Bigner DD, Papadopoulos N, Markowitz S, Willson JK, Kinzler KW and Vogelstein B (1994) Deletion of p16 and p15 genes in brain tumors. Cancer Res 54: 6353-6358

Kallioniemi OP, Kallioniemi A, Piper J, Isola J, Waldman FM, Gray JW and Pinkel D (1994) Optimizing comparative genomic hybridization for analysis of DNA sequence copy number changes in solid tumors. Genes Chromosomes Cancer 10: $231-243$

Karnes PS, Tuan NT, Cui MY, Raffel C, Gilles FH, Barranger JA and Ying KL (1992) Cytogenetic analysis of 39 pediatric central nervous system tumors. Cancer Genet Cytogenet 59: 12-19

McDonald J, Daneshvar L, Willert J, Matsumara K, Waldman F and Cogen P (1994) Physical mapping of chromosome $17 \mathrm{p} 13.3$ in the region of a putative tumor suppressor gene important in medulloblastoma. Genomics 23: 229-232

Meddeb M, Danglot G, Chudoba I, Venuat AM, Bénard J, Avet-Loiseau H, Vasseur B, Le Paslier D, Terrier-Lacombe MJ, Hartmann O and Bernheim A (1996) Additional copies of a $25 \mathrm{Mb}$ chromosomal region originating from 17q23. 1-qter are present in $90 \%$ of high-grade neuroblastomas. Genes Chromosomes Cancer 17: 156-165

Neumann E, Kalousek D, Norman M, Steinbok P, Cochrane D and Goddard K (1993) Cytogenetic analysis of 109 pediatric central nervous system tumors Cancer Genet Cytogenet 71: 40-49

Paszek-Vigier M, Talmant P, Méchinaud F, Garand R, Harousseau JL, Bataille R and Avet-Loiseau H (1997) Comparative genomic hybridization is a powerful tool, complementary to cytogenetics, to identify chromosomal abnormalities in childhood acute lymphoblastic leukemia. Br J Haematol 99: 589-596

Pietsch T, Waha A, Koch A, Kraus J, Albrecht S, Tonn J, Sorensen N, Berthold F, Henk B, Schmandt N, Wolf HK, von Deimling A, Wainwright B, ChenevixTrench G, Wiestler OD and Wicking C (1997) Medulloblastomas of the desmoplastic variant carry mutations of the human homologue of Drosophila patched. Cancer Res 57: 2085-2088

Reardon DA, Michalkiewicz E, Boyett JM, Sublett JE, Entrekin RE, Ragsdale ST, Valentine MB, Behm FG, Li H, Heideman RL, Kun LE, Shapiro DN and Look AT (1997) Extensive genomic abnormalities in childhood medulloblastoma by comparative genomic hybridization. Cancer Res 57: 4042-4047

Rouah E, Wilson DR, Armstrong DL and Darlington GJ (1989) N-myc amplification and neuronal differentiation in human primitive neuroectodermal tumors of the central nervous system. Cancer Res 49: 1797-1801

Scheurlen WG, Seranski P, Mincheva A, Kuhl J, Sorensen N, Krauss J, Lichter P, Poustka A and Wilgenbus KK (1997) High-resolution mapping of chromosome arm $17 \mathrm{p}$ in childhood primitive neuroectodermal tumors reveals a common chromosomal disruption within the the Smith-Magenis region, an unstable region in chromosome band 17p11.2. Genes Chromosomes Cancer 18: 50-58

Schutz BR, Scheurlen W, Krauss J, Du Manoir S, Joos S, Bentz M and Lichter P (1996) Mapping of chromosomal gains and losses in primitive neuroectodermal tumors by comparative genomic hybridization. Genes Chromosomes Cancer 16: $196-203$

Vagner-Capodano AM, Gentet JC, Gambarelli D, Pellissier JF, Gouzien M, Lena G, Genitori L, Choux M and Raybaud C (1992) Cytogenetic studies in 45 pediatric brain tumors. Pediatr Hematol Oncol 9: 223-235

Wasson JC, Saylors III LS, Zeltzer P, Friedman HS, Bigner SH, Burger PC, Bigner DD, Look AT, Douglass EC and Brodeur GM (1990) Oncogene amplification in pediatric brain tumors. Cancer Res 50: 2987-2990

Wolter M, Reifenberger J, Sommer C, Ruzicka T and Reifenberger G (1997) Mutations in the human homologue of the Drosophila segment polarity gene patched $(\mathrm{PTCH})$ in sporadic basal cell carcinomas of the skin and primitive neuroectodermal tumors of the central nervous system. Cancer Res 57: 2581-2585 